\title{
IDENTIFICATION OF THE MOST IMPORTANT EUROPEAN PRODUCTIVITY FACTORS THROUGH THE DIMENSION REDUCTION
}

\author{
Kornelia Lazanyi $^{1, \mathrm{a}, *}$, Pal Feher-Polgar ${ }^{2, \mathrm{~b}}$ and Imre Vida ${ }^{3, \mathrm{c}}$ \\ ${ }^{1}$ Keleti Faculty of Business and Management, Óbuda University, Bécsi 96/b, Budapest, Hungary \\ ${ }^{2}$ Keleti Faculty of Business and Management, Óbuda University, Bécsi 96/b, Budapest, Hungary \\ ${ }^{3}$ Szent István University, Páter K. 1, Godollo, H-2100, Hungary \\ alazanyi.kornelia@kgk.uni-obuda.hu, ${ }^{\mathrm{b}}$ feherpolgar.pal@ kgk.uni-obuda.hu, ${ }^{\mathrm{c}}$ ifo@ vidaimre.com \\ *Corresponding author
}

Cite as: Lazanyi, K., Feher-Polgar, P., Vida, I. (2020). Identification of the most important European productivity factors through the dimension reduction. Ekonomicko-manazerske spektrum, 14(1), 77-86.

Avaliable at: dx.doi.org/10.26552/ems.2020.1.77-86

\begin{abstract}
One of the basic factors that influence the production process and transfer its performance in it is the workforce. Despite the current era of innovation and automation, the human factor is irreplaceable. However, it is important to know what workers' productivity is and which factors affect work performance. Statistics show that people produce up to 80 per cent of their work in $20 \%$ of their daily working time. Working productivity is one of the most important factors in the company's efficiency and at the same time a decisive factor in its competitiveness. In the research paper, we focused on productivity and the factors that affect it. Firstly, we identified summarized factors, and then we processed the database in the form of a questionnaire survey, from which a total of 317 responses were obtained from the post-Soviet European countries, especially from the companies in the Czech Republic. Subsequently, from the package of these factors, we decided to choose those that are key in productivity. In order to process the key factors, dimension reduction was used in the SPSS program, which summarizes the data so that the relationships and patterns can be more easily interpreted and at the same time is based on the assumption of relationships between variables.
\end{abstract}

Keywords: productivity, factor analysis, dimension reduction

JEL Classification: C38, C55, D24

\section{Introduction}

The prerequisite for the success of any company is the long-term growth of the company, whether in terms of performance, revenue or profit. (Unger et al., 2020) Achieving long-term growth, ie increasing productivity-productivity, can be implemented by the company in several steps leading to the increase of partial productivity to achieve overall productivity, but first must know how to measure productivity, what is the relationship between productivity and long-term goals, which methods can increase business productivity. (Tekulova, 2014)

Productivity affects the economy at several levels, at the macro level (at the state level through indicators of GDP per worker), at the middle level (at the level of the sector) and at the micro-enterprise level (the level of individual producers and workers). Business performance indicators are used here. It mainly affects these selected entities. (Shamsaei et al., 2010; Pilinkiene, 2016; Battisti et al., 2018) 
Productivity is usually defined as the ratio between the volume of outputs and the volume of inputs. In other words, it measures how efficiently productive inputs, such as labor and capital, are used in the economy to create a given level of output. (Becker et al., 2018) Productivity is considered a key source of economic growth and competitiveness and, as such, is the basic statistical information for many international comparisons and evaluations of national performance. (Audretsch, 2007) Measurements are carried out at different levels: at the level of the whole economy, at the level of the economy and at the level of the company and the individual plant. Productivity data are used to investigate the impact of product regulation and the labor market on economic performance. (Nubler, 2014; Timmer, 2000) Productivity growth is an important basis for modeling the productive capacities of economies. It also allows analysts to determine capacity utilization, which in turn allows them to measure the position of the economy in the economic cycle and predict economic growth. In addition, production capacity is used to determine demand and inflationary pressures. (Cuadrado-Roura and MarotoSanchez, 2009)

Productivity on the micro level is strongly related to the motivation and satisfaction of employees. (DiMaria et al., 2000) Hence, it is not just the hard elements of an organisation that determine the productivity of a company, but the soft elements, such as the skills of employees, the leadership style applied and the organisational culture that determines staff behaviour (Salvarli and Kayiskan, 2018). Hence, present paper addresses a wide range of factors that might influence productivity. In line with the aim of this article the purpose was not to find the variables that have the closest relation with productivity, but to investigate a wide variety of potential influencers and provide a senseful grouping of them for companies that wish to increase their productivity. (Breinlich and Cunat, 2016)

The factor analysis used in the research paper based on the interrelationships between several variables identifies those that are interrelated. (Fang et al., 2004) It creates so-called factors from those that are closely related to each other, thus reducing the number of variables to a smaller number of factors. (Gaskin and Happell, 2014) In other words, factor analysis by examining the interrelationships between variables (correlation matrices) seeks to identify factors in a group of variables that reduce the number of variables. (Yong and Pearce, 2013; Joreskog, 1987)

Factor analysis is one of the multidimensional statistical methods and attempts to describe the properties of a set of variables using fewer new hidden variables, called factors. (Bernaards and Sijtsma, 1999) Using factors, it then tries to draw conclusions about the nature of the interdependencies of the original variables by describing a substantial part of the information. (Krishnakumar and Nagar, 2008) The beginnings of factor analysis go back to the beginning of the 20th century, when it became popular in social science research, especially in the field of psychology. The first practical introduction was made by the mathematician Karl Pearson and the well-known psychologist Charles Spearman in their famous measurement of intelligence. (Lovie and Lovie, 1993) Thus, factor analysis began to be used primarily in the field of psychometry, but later its applications were extended to many other disciplines, e.g. also in the Olympic Games - a well-known example of decathlon (Yan and Hong, 2007), as well as in economics, sociology, or other areas. (Feldstein, 2017)

The variables we examine, and of which there are many, can usually be called manifest variables. And reduced variables - factors can be called latent variables. Factor analysis is practically used to determine the interrelationships between variables; when creating questionnaires; when reducing a large number of variables to a limited number of Field factors. (Costello and Osborne, 2005) 


\section{Methodology}

We focused on the method of main components; it is a method where the uniqueness matrix $\Gamma 2$ is zero. Thus, it assumes that the variability of the source matrix can be reproduced without the rest utilizing the main components. It is an adequate orthogonal transformation that maintains all initial variability without residue. Then we discuss from the aspect of factor analysis about complete component analysis. If it reproduces only a substantial part of the variability, but not all, when reproducing through the main components, we speak of incomplete component analysis. For estimation of the parameters of the factor model, it is possible to write the object:

$$
\begin{gathered}
x_{1}=a_{11} y_{1}+a_{12} y_{2}+\cdots+a_{1 p} y_{p} \\
x_{2}=a_{21} y_{1}+a_{22} y_{2}+\cdots+a_{2 p} y_{p} \\
\cdots \\
x_{P}=a_{p 1} y_{1}+a_{p 2} y_{2}+\cdots+a_{p p} y_{p}
\end{gathered}
$$

However, the purpose is to find only " $m$ " common factors, so only the first $m$ main components $(y j, j=1, \ldots, m)$ are found, including the most significant proportion of variance of all the original variables. (Haiming and Wenlin, 2005; Sichel, 2019) The determination of the value of $m$ can be made based on proficient knowledge, the percentage of the variability drained by the given components. The main components are then modified into a factor model. For the variance of the common factors to be unitary, each principal component is distributed by its standard deviation $\mathrm{S}_{\mathrm{jj}}{ }^{2}$, which is the diagonal element of the matrix $\mathrm{S}$, a common factor is created (Basto and Pereira, 2012):

... afterward, we can express $y_{j}$

$$
F_{j}=\frac{y_{j}}{\sqrt{S_{j j}^{2}}}
$$

$$
y_{j}=F_{j} * \sqrt{S_{j j}^{2}}
$$

After superseding into the equation and using only the first $\mathrm{m}$ components, we summarize the other components into specific factors as follows:

$$
e_{i}=a_{m+1, i} F_{m+1} * \sqrt{S_{m+1, m+1}^{2}}+\cdots+a_{p i} F_{p} * \sqrt{S_{p p}^{2}}, y_{j}=F_{j} * \sqrt{S_{j j}^{2}}
$$

then we get:

$$
\begin{gathered}
x_{1}=l_{11} F_{1}+l_{12} F_{2}+\cdots+l_{1 m} F_{m}+e_{1} \\
x_{2}=l_{21} F_{1}+l_{22} F_{2}+\cdots+l_{2 m} F_{m}+e_{2} \\
\cdots \\
x_{p}=l_{p 1} F_{1}+l_{p 2} F_{2}+\cdots+l_{p m} F_{m}+e_{p}
\end{gathered}
$$

The factor load can be expressed as $l_{i j}=a_{i j} \sqrt{S_{j j}^{2}}$. 
This transformed the main components into factors. Given that factor analysis is about finding common factors whose number is less than the number of original variables, their reasonable interpretation is essential, so it is crucial to rotate the elements. (Weaver and Maxwell, 2014)

The goal of factor rotation is to improve the interpretability of the solution of factors by achieving simple structures. Based on the solution of factor analysis, we get to estimate the factor scores. (Joreskog, 1987)

Factor scores represent the values of factors or non-measurable, latent variables. Estimates of factor saturations and estimates of specific variances use estimate factor scores. Estimates can be based on both non-rotated and rotated solutions. (Haiming and Wenlin, 2005)

\section{Results}

In this research paper, we focused on productivity and, overall, we were able to identify up to 33 factors that affected the company's productivity based on an analysis of the literature. Based on these factors, a questionnaire was compiled and sent to various companies in the Czech Republic. The total number of responses received that entered the analysis was 317 . Subsequently, it is necessary to use factor analysis to eliminate the number of identified factors to reach the number of important ones.

The processing of the factor analysis was preceded by the selection of input data and their suitability assessment. As mentioned above, we obtained the data based on electronic inquiries. We assume that the input variables are correlated with each other to confirm the existence of common causes. We verified the interdependencies and evaluation of the input variables based on the Kaiser - Meyer - Olkin (KMO) criterion.

At the same time, we performed the Bartlett test, based on which we verified the hypothesis:

HO: Production indicators are not correlated with each other.

H1: Production indicators are correlated with each other.

Table 1 shows the results of the KMO and Bartlett test. Given a KMO value of 0.758 , it indicates the suitability of the processed data for structure detection. We test the null hypothesis by Bartlett's sphericity test, and since this value is 0.000 , factor analysis is useful in these data. We reject hypothesis $\mathrm{H} 0$ and accept alternative hypothesis $\mathrm{H} 1$.

Table 1: KMO and Bartlett's Test

\begin{tabular}{|c|c|c|}
\hline \multicolumn{3}{|l|}{ KMO and Bartlett's Test } \\
\hline \multicolumn{2}{|c|}{ Kaiser-Meyer-Olkin Measure of Sampling Adequacy. } & .758 \\
\hline \multirow{3}{*}{ Bartlett's Test of Sphericity } & Approx. Chi-Square & 563.159 \\
\hline & df & 528 \\
\hline & Sig. & .000 \\
\hline
\end{tabular}

Source: Output

The number of common factors is determined based on the criterion of explained variability and common factors explaining about $60 \%$ of the total variability. We decided to apply the given method of determining the number of factors to our variables as well. In Table 2, we included $59.461 \%$ of the explained variability through 15 common factors.

Table 2: Total Variance Explained 


\begin{tabular}{|c|c|c|c|c|c|c|c|c|c|}
\hline \multirow{2}{*}{ Comp. } & \multicolumn{3}{|c|}{ Initial Eigenvalues } & \multicolumn{3}{|c|}{$\begin{array}{l}\text { Extraction Sums of Squared } \\
\text { Loadings }\end{array}$} & \multicolumn{3}{|c|}{$\begin{array}{l}\text { Rotation Sums of Squared } \\
\text { Loadings }\end{array}$} \\
\hline & Total & $\begin{array}{l}\% \text { of } \\
\text { Variance }\end{array}$ & $\begin{array}{l}\text { Cumulative } \\
\%\end{array}$ & Total & $\begin{array}{l}\% \text { of } \\
\text { Variance }\end{array}$ & Cumulative $\%$ & Total & $\begin{array}{l}\% \text { of } \\
\text { Variance }\end{array}$ & Cumulative \% \\
\hline 1 & 1.587 & 4.810 & 4.810 & 1.587 & 4.810 & 4.810 & 1.456 & 4.411 & 4.411 \\
\hline 2 & 1.554 & 4.709 & 9.520 & 1.554 & 4.709 & 9.520 & 1.350 & 4.090 & 8.501 \\
\hline 3 & 1.544 & 4.678 & 14.197 & 1.544 & 4.678 & 14.197 & 1.347 & 4.081 & 12.582 \\
\hline 4 & 1.477 & 4.476 & 18.674 & 1.477 & 4.476 & 18.674 & 1.346 & 4.077 & 16.659 \\
\hline 5 & 1.454 & 4.407 & 23.081 & 1.454 & 4.407 & 23.081 & 1.344 & 4.072 & 20.731 \\
\hline 6 & 1.384 & 4.194 & 27.275 & 1.384 & 4.194 & 27.275 & 1.336 & 4.050 & 24.781 \\
\hline 7 & 1.339 & 4.056 & 31.331 & 1.339 & 4.056 & 31.331 & 1.335 & 4.045 & 28.826 \\
\hline 8 & 1.286 & 3.896 & 35.227 & 1.286 & 3.896 & 35.227 & 1.312 & 3.977 & 32.802 \\
\hline 9 & 1.270 & 3.849 & 39.077 & 1.270 & 3.849 & 39.077 & 1.307 & 3.960 & 36.763 \\
\hline 10 & 1.228 & 3.720 & 42.796 & 1.228 & 3.720 & 42.796 & 1.291 & 3.912 & 40.674 \\
\hline 11 & 1.178 & 3.569 & 46.366 & 1.178 & 3.569 & 46.366 & 1.289 & 3.907 & 44.581 \\
\hline 12 & 1.138 & 3.449 & 49.814 & 1.138 & 3.449 & 49.814 & 1.279 & 3.875 & 48.456 \\
\hline 13 & 1.092 & 3.310 & 53.124 & 1.092 & 3.310 & 53.124 & 1.275 & 3.862 & 52.318 \\
\hline 14 & 1.076 & 3.260 & 56.384 & 1.076 & 3.260 & 56.384 & 1.189 & 3.603 & 55.921 \\
\hline 15 & 1.015 & 3.077 & 59.461 & 1.015 & 3.077 & 59.461 & 1.168 & 3.540 & 59.461 \\
\hline
\end{tabular}

Extraction Method: Principal Component Analysis.

Source: Output

The number of factors can also be determined using a "scree plot," which graphically shows the relationship between the number of the factors on the $\mathrm{x}$-axis and the eigenvalue on the $\mathrm{y}$ axis and determines the number of common factors based on the breakpoint. In this case, it is number 15 . This number is based on a percentage of the explained variability, and it is true that whose surface is flatter and includes less variability.

The result of the factor analysis is a matrix of correlation coefficients between indicators and factors. The values of the matrix represent factor saturations and explain how the factor significantly affects the indicator but also how the indicator significantly indicates the factor. As high factor saturation has occurred in the analysis, it is necessary to rotate the factors. By rotating the factors, we obtained a simple structure, and we reduced the numerous productivity factors for which the monitored indicators have a high load. Rotation maximizes the load on each variable while minimizing the load on all other factors. 
Identification of the most important European productivity factors through the dimension reduction

Authors: Kornelia Lazanyi, Pal Feher-Polgar and Imre Vida

Table 3: Rotated Component Matrix

\begin{tabular}{|c|c|c|c|c|c|c|c|c|c|c|c|c|c|c|c|c|}
\hline \multicolumn{17}{|c|}{ Rotated Component Matrix ${ }^{a}$} \\
\hline & \multirow{2}{*}{ Productivity factor } & \multicolumn{15}{|c|}{ Component } \\
\hline \multirow{5}{*}{$\mathrm{F} 1$} & & 1 & 2 & 3 & 4 & 5 & 6 & 7 & 8 & 9 & 10 & 11 & 12 & 13 & 14 & 15 \\
\hline & new equipment & 0.856 & 0.171 & 0.103 & 0.122 & 0.178 & 0.14 & 0.137 & 0.136 & -0.056 & 0.25 & 0.147 & -0.224 & 0.012 & 0.052 & 0.111 \\
\hline & maintained equipment & 0.721 & 0.292 & 0.133 & 0.159 & 0.023 & 0.202 & 0.228 & 0.195 & 0.038 & -0.165 & 0.061 & -0.063 & 0.192 & 0.245 & -0.202 \\
\hline & physical capital & 0.689 & 0.163 & 0.271 & 0.056 & 0.158 & 0.068 & -0.076 & 0.104 & 0.236 & 0.053 & -0.096 & -0.283 & 0.083 & -0.025 & -0.022 \\
\hline & parking place & 0.671 & 0.05 & 0.08 & 0.029 & 0.078 & 0.189 & 0.038 & 0.178 & 0.124 & 0.135 & 0.23 & -0.052 & 0.049 & 0.11 & -0.013 \\
\hline \multirow{2}{*}{$\mathrm{F} 2$} & relax zone & 0.103 & 0.645 & 0.039 & 0.16 & 0.195 & 0.183 & 0.015 & -0.192 & 0.125 & -0.075 & -0.155 & -0.014 & -0.073 & 0.032 & 0.09 \\
\hline & baby sitting & 0.013 & 0.635 & 0.173 & 0.066 & 0.079 & 0.212 & 0.037 & 0.111 & 0.114 & -0.006 & -0.107 & -0.045 & 0.199 & -0.084 & 0.038 \\
\hline \multirow{2}{*}{ F3 } & smart equipment & 0.06 & 0.258 & 0.652 & 0.001 & 0.084 & 0.064 & 0.101 & 0.001 & 0.192 & 0.229 & -0.11 & 0.051 & -0.052 & 0.036 & -0.116 \\
\hline & specialized equipment & 0.1 & 0.118 & 0.623 & 0.088 & 0.141 & -0.156 & 0.044 & -0.152 & -0.154 & 0.008 & 0.187 & 0.102 & -0.022 & -0.154 & -0.075 \\
\hline \multirow{2}{*}{$\mathrm{F} 4$} & language courses & 0.237 & 0.002 & 0.132 & 0.831 & 0.062 & 0.135 & 0.151 & 0.244 & -0.126 & 0.145 & -0.204 & 0.088 & -0.132 & 0.114 & -0.076 \\
\hline & additional education & 0.07 & 0.183 & 0.042 & 0.634 & -0.002 & 0.17 & -0.005 & 0.04 & 0.091 & -0.042 & 0.097 & -0.017 & 0.098 & -0.055 & -0.005 \\
\hline \multirow{2}{*}{ F5 } & team buildings & 0.042 & 0.029 & 0.119 & 0.204 & 0.735 & 0.059 & -0.039 & 0.195 & 0.039 & -0.02 & -0.132 & -0.027 & -0.006 & 0.104 & -0.011 \\
\hline & work in teams & 0.121 & 0.045 & 0.019 & -0.033 & 0.705 & 0.001 & 0.06 & -0.139 & 0.078 & -0.088 & 0.069 & 0.045 & -0.014 & -0.166 & -0.002 \\
\hline \multirow{3}{*}{ F6 } & software & -0.03 & 0.101 & 0 & -0.049 & 0.103 & 0.785 & 0.072 & 0.127 & -0.018 & 0.144 & -0.078 & 0.166 & -0.038 & 0.054 & 0.161 \\
\hline & knowledge management & 0.094 & 0.068 & 0.042 & 0.236 & 0.119 & 0.688 & 0.2 & -0.079 & 0.211 & -0.009 & -0.182 & -0.147 & -0.034 & 0 & 0.118 \\
\hline & training programs & 0.164 & 0.186 & 0.172 & 0.183 & 0.158 & 0.62 & -0.017 & 0.197 & 0.121 & 0.243 & 0.08 & 0.115 & 0.056 & 0.056 & 0.034 \\
\hline \multirow{2}{*}{ F7 } & library card & 0.041 & 0.018 & 0.084 & -0.058 & -0.017 & 0.112 & 0.752 & 0.047 & 0.165 & -0.159 & 0.158 & 0.066 & -0.119 & 0.146 & -0.038 \\
\hline & gym & 0.019 & 0.071 & 0.179 & 0.127 & -0.075 & 0.077 & 0.599 & 0.038 & -0.021 & 0.247 & 0.026 & -0.047 & 0.021 & 0.05 & -0.017 \\
\hline \multirow{2}{*}{ F8 } & additional vacations & 0.109 & -0.038 & -0.006 & 0.032 & 0.023 & 0.112 & -0.047 & 0.741 & 0.017 & 0.108 & 0 & 0.028 & 0.098 & -0.028 & 0.132 \\
\hline & holiday allowance & 0.056 & 0.024 & 0.156 & 0.029 & 0.039 & 0.063 & -0.007 & 0.657 & 0.096 & 0.032 & 0.016 & -0.041 & 0.168 & 0.045 & 0.166 \\
\hline F9 & flexible time & 0.201 & 0.16 & 0.189 & -0.036 & 0.179 & 0.115 & 0.143 & 0.071 & 0.728 & -0.084 & 0.142 & -0.029 & -0.144 & 0.01 & -0.004 \\
\hline
\end{tabular}




\begin{tabular}{|c|c|c|c|c|c|c|c|c|c|c|c|c|c|c|c|c|}
\hline \multicolumn{17}{|c|}{ Rotated Component Matrix ${ }^{a}$} \\
\hline & \multirow{2}{*}{ Productivity factor } & \multicolumn{15}{|c|}{ Component } \\
\hline & & 1 & 2 & 3 & 4 & 5 & 6 & 7 & 8 & 9 & 10 & 11 & 12 & 13 & 14 & 15 \\
\hline & health care & -0.035 & 0.053 & 0.051 & 0.152 & 0.115 & 0.016 & 0.203 & 0.108 & 0.565 & 0.018 & 0.057 & 0.003 & -0.009 & 0.17 & 0.16 \\
\hline \multirow{3}{*}{ F10 } & retirement savings & 0.125 & 0.11 & 0.083 & 0.151 & 0.244 & -0.018 & 0.016 & -0.03 & 0.21 & 0.665 & -0.266 & 0.121 & -0.064 & 0.029 & -0.09 \\
\hline & financial bonuses & -0.17 & 0.231 & 0.148 & 0.135 & 0.18 & -0.13 & 0.103 & 0.122 & 0.156 & 0.642 & 0.283 & 0.104 & -0.228 & 0.104 & -0.017 \\
\hline & company car & 0.111 & 0.055 & 0.16 & 0.042 & 0.164 & 0.092 & -0.037 & 0.016 & 0.204 & -0.009 & 0.627 & 0.01 & 0.072 & -0.264 & 0.067 \\
\hline \multirow[t]{2}{*}{ F11 } & company phone & -0.048 & 0.138 & 0.118 & 0.048 & 0.118 & 0.264 & -0.044 & 0.069 & 0.081 & -0.041 & 0.707 & -0.008 & 0.031 & 0.012 & -0.14 \\
\hline & company PC & 0.099 & 0.096 & 0.134 & 0.054 & 0.077 & -0.164 & 0.06 & -0.027 & -0.137 & -0.019 & 0.544 & -0.022 & 0.036 & 0.073 & -0.068 \\
\hline \multirow{2}{*}{ F12 } & conferences & 0.137 & 0.146 & 0.137 & 0.048 & -0.017 & 0.247 & 0.186 & 0.125 & 0.123 & 0.277 & 0.061 & 0.692 & 0.138 & 0.139 & 0.258 \\
\hline & business trip & -0.061 & 0.105 & -0.061 & 0.108 & -0.014 & -0.059 & 0.05 & 0.007 & -0.076 & -0.078 & -0.006 & 0.628 & -0.083 & 0.267 & -0.182 \\
\hline \multirow{2}{*}{ F13 } & personal evaluation & 0.109 & 0.106 & 0.109 & 0.181 & 0.17 & 0.201 & 0.117 & 0.039 & 0.098 & -0.026 & 0.262 & 0.166 & 0.572 & 0.13 & -0.001 \\
\hline & working atmosphere & 0.099 & 0.109 & -0.016 & 0.195 & -0.062 & -0.029 & 0.261 & -0.048 & 0.161 & -0.041 & 0.159 & 0.133 & 0.671 & -0.122 & -0.079 \\
\hline \multirow{2}{*}{ F14 } & praise & 0.142 & 0.211 & 0.015 & 0.144 & -0.086 & -0.002 & 0.096 & -0.188 & 0.196 & -0.004 & 0.014 & 0.198 & -0.034 & 0.622 & -0.119 \\
\hline & employee of a month & 0.103 & -0.006 & 0.274 & -0.137 & 0.076 & 0.055 & 0.043 & 0.108 & -0.033 & 0.099 & -0.026 & -0.107 & -0.056 & 0.542 & -0.225 \\
\hline $\mathrm{F} 15$ & clothing allowance & 0.139 & 0.014 & -0.033 & 0.095 & 0.088 & 0.013 & 0.139 & 0.254 & 0.173 & 0.259 & -0.111 & 0.058 & -0.064 & -0.101 & 0.668 \\
\hline
\end{tabular}

Extraction Method: Principal Component Analysis.

Rotation Method: Varimax with Kaiser Normalization. ${ }^{a}$

a. Rotation converged in 23 iterations.

Source: Output 
After factor rotation, we acquired a factor-net solution, which means that significant factor saturation of a given indicator was achieved with one factor. From the original 33 variables, we obtained 15 new ones, due to the factual fundamentals. The way in which the factor analysis conjunct the individual indicators into factors is shown in Table 3.

\section{Discussion}

Based on the factor analysis, the factors influencing working productivity were reduced by more than half, from the original 33 to 15 factors. Subsequently, it is possible to work with the identified factors, or continue the analysis and generate a factor score, which represents a matrix of numbers that can be used in further analysis. Factor analysis is a very complex analysis and requires several assumptions to be met. For example, it is a test of the normality or homoskedasticity of residues, or autocorrelation. At the same time, an in-depth analysis of the factors is needed. In our case, the database could be supplemented by other factors affecting productivity.

As it is visible from table 3 , most factors influencing productivity are costly and/or take time. Hence, before making a decision for one or the other, owners and managers have to analyse the costs and benefits of their application. What is more, for a more thorough understanding, the costs and potential threats of the alternative solutions have to be considered before making a choice.

A simple example, that most companies can relate to, is the case of company phones and PCs. Some of the companies provide their employees with all necessary tools in order to regulate their usage. Some other companies on the other hand require their staff to use their personal gadgets for company purposes. This latter solution is so wide-spread that it already has an acronym in management literature: BYOD. The name stands for Bring Your Own Device (Zahadat et al., 2015). In general, this means that employees are supposed to use their own property - smartphones, laptops and tablets - for business activities. As it is easily understood, the most important advantage of the application of BYOD for the employer is the convenience and the rise of effectiveness obtained by utilizing the resources - that would have been spent on these tools - elsewhere (Belanger and Crossler, 2019). Additional rise in productivity may stem from the convenient usage of the self-owned device. The improvement in productivity derives from the fact that the employee already knows the usage of its smart device. Thus, the employee already has a knowledge that can be applied for work. This shortens the time for the adaptations for the new forms of working.

However, as emphasized above, there are two sides of the coin. Besides loosing a potential tool for motivating employees, information security questions also arise when accessing company information from private ICT tools. In order to mitigate the risks in a BYOD solution companies can apply mobile device management solutions which can lower the risks of some security aspects. These solutions are among others capable of managing data stored on devices, protecting critical files and services from modification and termination, securing communication between the device and the ICT infrastructure or locating lost devices (Tse et al., 2016). Nonetheless, the utilisation of security software solutions is only a step forward for security and not the final answer. Well-designed security policies and rules are also necessary, and personnel to manage such systems (Serenko and Turel, 2019). All in all, although the company is not spending on purchasing company phones or PCs for its employees, but spends (most of the time) a lot more money on systems that enable the safe use of the employees own devices. 
For this very reason, the factors analysed in our research are the starting point and not the answer for a production improving management decision. While the wide array of potential solutions might make the increase of productivity an easy development, a thorough analysis of every factor cannot be avoided.

\section{Conclusion}

Factor analysis helps us reduce the number of variables that can potentially measure the same things. So, from confusing questions, we get, for example, 2 variables that tell us something specific. Of course, this significantly reduces the data. The aim of present paper was to identify key productivity factors in companies in the Czech Republic. For this reason, an indepth search of the literature dealing with the issue was needed to identify as many factors as possible. Subsequently, a questionnaire was prepared and sent to the parties, and a total of 317 responses were obtained. These input data were verified using the KMO test and the Bartlett test and were evaluated as suitable for factor analysis. At the basis of the analysis, we managed to eliminate the data by more than half and a simpler list of 15 productivity factors was created. In terms of benefits, this publication focused on the elaboration of the basic terminology of productivity of workplaces. It also emphasized the importance of a comprehensive investigation of each factor's costs, benefits, and that of their alternative solutions. In addition, the paper proved to be able to identify the key productivity factors using dimension reduction on a sample of companies form the Czech Republic. However, since the factor analysis's results were stable, the findings of present paper might be generalized and applied for companies across the world.

\section{Acknowledgment}

This paper is an output of a research supported by the New National Excellency Program UNKP2019.

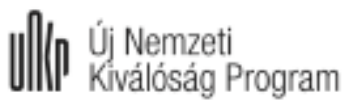

\section{References}

Audretsch, D. B. (2007). Entrepreneurship capital and economic growth. Oxford Review of Economic Policy, 23(1), pp. 63-78.

Basto, M. and Pereira, J. M. (2012). An SPSS R-menu for ordinal factor analysis. Journal of statistical software, 46(4), pp. 1-29.

Battisti, M., Del Gatto, M. and Parmeter, Ch. F. (2018). Labor productivity growth: Disentangling technology and capital accumulation. Journal of Economic Growth, 23(1), pp. 111-143.

Becker, T. E., Kernan, M. C., Clark, K. D. et al. (2018). Dual commitments to organizations and professions: Different motivational pathways to productivity. Journal of Management, 44(3), pp. 1202-1225.

Belanger, F. and Crossler R. E. (2019) Dealing with digital traces: Understanding protective behaviors on mobile devices in The Journal of Strategic Information Systems, 28(1), pp. 34-49.

Bernaards, C. A., and Sijtsma, K. (1999). Factor analysis of multidimensional polytomous item response data suffering from ignorable item nonresponse. Multivariate Behavioral Research, 34(3), pp. 277-313.

Breinlich, H. and Cunat, A. (2016). Tariffs, trade and productivity: A quantitative evaluation of heterogeneous firm models. Economic Journal, 126, pp. 1660-1702.

Costello, A. B. and Osborne, J. (2005). Best practices in exploratory factor analysis: Four recommendations for getting the most from your analysis. Practical Assessment, Research, and Evaluation, 10(1), pp. 7.

Cuadrado-Roura, J. R. and Maroto-Sanchez, A. (2009). Regional productivity convergence and changes in the productive structure. Regional Policy, Economic Growth and Convergence, pp. 149-170, Springer, Berlin, Heidelberg. 
DiMaria, C. H., Peroni, C. and Sarracino, F. (2020). Happiness matters: Productivity gains from subjective wellbeing. Journal of Happiness Studies, 21(1), pp. 139-160.

Fang, D. P., Xie, F., Huang, X. Y. and Li, H. (2004). Factor analysis-based studies on construction workplace safety management in China. International Journal of Project Management, 22(1), pp. 43-49.

Feldstein, M. (2017). Underestimating the real growth of GDP, personal income, and productivity. Journal of Economic Perspectives, 31(2), pp. 145-163.

Gaskin, C. J. and Happell, B. (2014). On exploratory factor analysis: A review of recent evidence, an assessment of current practice, and recommendations for future use. International Journal of Nursing Studies, 51(3), pp. 511-521.

Haiming, L. and Wenlin, Z. (2005). The Relationship between Principal Component Analysis and Factor Analysis and SPSS Software-To Discuss with Comrade Liu Yumei, Lu Wendaietc, Statistical Research, 3, pp. 65-69.

Joreskog, K. G. (1978). Structural analysis of covariance and correlation matrices. Psychometrika, 43(4), pp. 443477.

Krishnakumar, J. and Nagar, A. L. (2008). On exact statistical properties of multidimensional indices based on principal components, factor analysis, MIMIC and structural equation models. Social Indicators Research, 86(3), pp. 481-496.

Lovie, A. D. and Lovie, P. (1993). Charles Spearman, Cyril Burt, and the origins of factor analysis. Journal of the History of the Behavioral Sciences, 29(4), pp. 308-321.

Nübler, I. (2014). A theory of capabilities for productive transformation: Learning to catch up. Transforming Economies, 113.

Pilinkiene, V. (2016). Trade openness, economic growth and competitiveness. The case of the central and eastern European countries. Engineering Economics, 27(2), pp. 185-194.

Salvarli, M. S. and Kayiskan, D. (2018). An analysis of McKinsey 7-s model and its application on organizational efficiency. International Journal of Scientific and Technological Research, pp. 2422-8702.

Serenko, A. and Turel, O. (2019) A dual-attitude model of system use: The effect of explicit and implicit attitudes. Information \& Management, 56(5), pp. 657-668.

Shamsaei, A., Pourshahid, A. and Amyot, D. (2010). Business process compliance tracking using key performance indicators. International Conference on Business Process Management, pp. 73-84, Springer, Berlin, Heidelberg.

Sichel, D. E. (2019). Productivity measurement: Racing to keep up. Annual Review of Economics, 11, pp. 591614.

Tekulova, Z. (2014). Produktivitapodniku, Schválila Vedecká rada Strojnícke jfakulty STU v Bratislave.

Timmer, M. P. and Szirmai, A. (2000). Productivity growth in Asian manufacturing: the structural bonus hypothesis examined. Structural Change and Economic Dynamics, 11(4), pp. 371-392.

Tse, D., L. Wang L. and Li, Y. Mobility management for enterprises in BYOD deployment. 2016 IEEE Trustcom/BigDataSE/ISPA, Tianjin, pp. 638-645.

Unger, O., Szczesny, A. and Holderried, M. (2020). Does performance pay increase productivity? Evidence from a medical typing unit. Management Accounting Research, 47, pp. 100649.

Weaver, B. and Maxwell, H. (2014). Exploratory factor analysis and reliability analysis with missing data: A simple method for SPSS users. The Quantitative Methods for Psychology, 10(2), pp. 143-152.

Yan, W. A. N. G. and Hong, Z. H. O. U. (2007). Multi-factor Analysis on Competitive Failure of Chinese Race Walking Athletes in the 28th Olympic Games. Journal of Xi'an Physical Education University, 1.

Yong, A. G. and Pearce, S. (2013). A beginner's guide to factor analysis: Focusing on exploratory factor analysis. Tutorials in Quantitative Methods for Psychology, 9(2), pp. 79-94.

Zahadat, N, Blessner, P, Blackburn, T. and Olson B. A. (2015) BYOD security engineering: A framework and its analysis. Computers \& Security, 55, pp. 81-99. 